\title{
The 2G allele of promoter region of Matrix metalloproteinase-I as an essential pre-condition for the early onset of oral squamous cell carcinoma
}

\author{
Rishiho Nishizawa1, Masaki Nagata*2, Arhab A Noman², \\ Nobutaka Kitamura², Hajime Fujita², Hideyuki Hoshina ${ }^{2}$, Takehiko Kubota ${ }^{3}$, \\ Manami Itagaki ${ }^{3}$, Susumu Shingaki ${ }^{4}$, Makoto Ohnishi ${ }^{5}$, Hiroshi Kurita1, \\ Kouji Katsura ${ }^{6}$, Chikara Saito ${ }^{4}$, Hiromasa Yoshie ${ }^{3}$ and Ritsuo Takagi ${ }^{2}$
}

Address: ${ }^{1}$ Department of Dentistry and Oral Surgery, Shinshu University School of Medicine, Asahi 3-1-1, Matsumoto 390-8621, Japan, ${ }^{2}$ Division of Oral and Maxillofacial Surgery, Niigata University Graduate School of Medical and Dental Sciences, Gakkocho-dori 2-5274, Niigata 951-8514, Japan, ${ }^{3}$ Division of Periodontology, Niigata University Graduate School of Medical and Dental Sciences, Gakkocho-dori 2-5274, Niigata 9518514, Japan, ${ }^{4}$ Division of Reconstructive Surgery for Oral and Maxillofacial Region, Niigata University Graduate School of Medical and Dental Sciences, Gakkocho-dori 2-5274, Niigata 951-8514, Japan, 5 Division of Dental Clinic and Oral Surgery, Nagaoka Red Cross Hospital, Terashimamachi 297-1, Nagaoka 940-2085, Japan and ${ }^{6}$ Division of Oral and Maxillofacial Radiology, Niigata University Graduate School of Medical and Dental Sciences, Gakkocho-dori 2-5274, Niigata 951-8514, Japan

Email: Rishiho Nishizawa - ni4zawa@hsp.md.shinshu-u.ac.jp; Masaki Nagata* - nagata@dent.niigata-u.ac.jp; Arhab A Noman - arhabn@dent.niigata-u.ac.jp; Nobutaka Kitamura - nktmr@m12.alpha-net.ne.jp; Hajime Fujita - fujita1@dent.niigata-u.ac.jp; Hideyuki Hoshina - hoshina@dent.niigata-u.ac.jp; Takehiko Kubota - kubota@dent.niigata-u.ac.jp; Manami Itagaki - ita@dent.niigata-u.ac.jp; Susumu Shingaki - shigaki@dent.niigata-u.ac.jp; Makoto Ohnishi - namakoto@dent.niigata-u.ac.jp; Hiroshi Kurita - hkurita@hsp.md.shinshuu.ac.jp; Kouji Katsura - katsu@dent.niigata-u.ac.jp; Chikara Saito - ckrsaito@dent.niigata-u.ac.jp; Hiromasa Yoshie - yoshie@dent.niigatau.ac.jp; Ritsuo Takagi - takagi@dent.niigata-u.ac.jp

* Corresponding author

Published: 5 October 2007

BMC Cancer 2007, 7:187 doi:10.1 186/147/-2407-7-187
Received: 19 March 2007

Accepted: 5 October 2007

This article is available from: http://www.biomedcentral.com/I47/-2407/7//87

(C) 2007 Nishizawa et al.; licensee BioMed Central Ltd.

This is an Open Access article distributed under the terms of the Creative Commons Attribution License (http://creativecommons.org/licenses/by/2.0), which permits unrestricted use, distribution, and reproduction in any medium, provided the original work is properly cited.

\begin{abstract}
Background: Matrix metalloproteinase (MMP) is known to be involved in the initial and progressive stages of cancer development, and in the aggressive phenotypes of cancer. This study examines the association of single nucleotide polymorphisms in promoter regions of MMP-I and MMP-3 with susceptibility to oral squamous cell carcinoma (OSCC).

Methods: We compared 170 Japanese OSCC cases and 164 healthy controls for genotypes of MMP-I and MMP-3.

Results: The frequency of the MMP-I 2G allele was higher and that of the IG homozygote was lower in the OSCC cases $(p=0.034)$. A multivariate logistic regression analysis revealed that subjects who were 45 years old or older had a significantly increased (2.47-fold) risk of OSCC $(95 \% \mathrm{Cl}$ I.47-4.14, $p=0.0006)$, and those carrying the MMP-I $2 \mathrm{G}$ allele had a 2.30 -fold risk $(95 \% \mathrm{Cl} 1.15-4.58, p=0.018)$, indicating independent involvement of these factors in OSCC. One of the key discoveries of this research is the apparent reduction of the MMP-I IG/IG and IG/2G genotype distributions among the early onset OSCC cases under the ages of 45 years. It should be noted that the tongue was the primary site in $86.2 \%$ of these early onset cases. This could suggest the specific carcinogenic mechanisms, i.e. specific carcinogenic stimulations and/or genetic factors in the tongue.
\end{abstract}

Conclusion: Since the $2 \mathrm{G}$ allele is a majority of the MMP-I genotype in the general population, it seems to act as a genetic pre-condition in OSCC development. However this report suggests a crucial impact of the MMP-I $2 \mathrm{G}$ allele in the early onset OSCC. 


\section{Background}

Matrix metalloproteinase (MMP)-1 (Collagenase-1) is a major proteinase of the MMP family that specifically degrades type I collagen, which is a major component of the extracellular matrix (ECM), as well as other fibrillar collagens of types II, III, V and IX [1,2]. MMP-3 (Stromelysine-1) is responsible for degradation of type IV collagen, which forms the basement membrane, and collagen $\mathrm{V}$, IX, X [3]. MMP-3 also has a role in activation of proMMP-1 in tumor tissue into the active form of MMP-1 [4]. Gene expression data in our previous report demonstrated enhanced expression of MMP family genes in OSCC tissues, and suggested correlation of high expression levels of MMP-1 and MMP-3 with aggressive behavior, such as metastasis, and clinical prognosis [5]. Similar correlations have been reported in pharyngeal, colon and various other tumor types [6-8]. Colocalization of MMP-1 and $M M P-3$ with destruction of ECM in the invasive front of cancer tissue suggests a direct role in cancer invasion [9].

It has also been shown that a function of MMPs affects susceptibility to different kinds of carcinoma. To date, polymorphisms of the promoter domain have been described in $M M P-1,-3,-9,-12$ to influence the expression level of the genes [10]. A 2G type of single nucleotide polymorphism (SNP) at -1607 bp site in the promoter domain of MMP-1 creates a sequence, 5'-GGA-3,' that is the core recognition sequence of the binding site for Ets family transcription factors. The $2 \mathrm{G}$ type promoter results in higher transcription activity of the MMP-1 gene than does a $1 \mathrm{G}$ type promoter [11]. A 5A type promoter at 1171 bp site of MMP-3 is also known to have a twofold higher transcriptional activity in vitro than that of a $6 \mathrm{~A}$ type [12]. It has been documented that the 2G type SNP of MMP-1 confers increased susceptibility to colorectal [13], ovarian [14], lung [15], endometrial [16], renal cell [17] and head and neck [18] cancers; and the 5A type SNP of $M M P-3$ is associated with an increased susceptibility to breast cancer [19].

An in situ hybridization study revealed that MMP-1 expression in normal oral mucosa is controlled at a low level, whereas a remarkably elevated expression level is observed in cases of oral epithelial dysplasia, which becomes even higher in cases of OSCC [20]. It has also been documented that cases of oral epithelial dysplasia showing high expression level of MMP-1 developed into OSCC at higher frequency than cases with low expression of MMP-1 [21]. Taking all the observations noted above into consideration, it seems likely that MMPs may serve as key factors in all stages of the OSCC progression from carcinogenesis in the early precancerous condition to the advanced invasive and metastatic phases.
The purpose of this study is to document the effect of genomic polymorphisms of MMP genes in the development of OSCC. We compared genotype distribution in the promoter domains of the functional SNPs that influence the transcriptional activity of $M M P-1$ and $M M P-3$ between OSCC patients and healthy control groups. Multivariate analysis was effectively used to assess correlations among parameters such as OSCC, the genotypes, age and sex. In this report, we describe the role of functional SNP of the $M M P-1$ gene in susceptibility to OSCC and, as a remarkable finding; we discuss the crucial impact of the MMP-1 $2 \mathrm{G}$ allele in the development of OSCC in younger individuals.

\section{Methods \\ Study subjects}

The tested cases were all unrelated native Japanese comprising 170 cases of OSCC (107 males, 63 females; average age $56.5 \pm 13.9$ years) who were histopathologically diagnosed as differentiated squamous cell carcinoma. The controls comprised 164 (104 males, 60 females) healthy subjects who did not have a history of malignant tumors and were frequency-matched to the cases by age ( \pm 5 years; average age $51.5 \pm 14.7$ years). All OSCC subjects were patients who had been treated in the Dental Department of Niigata University Medical and Dental Hospital, Special Dental Care and Oral Surgery, Shinshu University Hospital, and Division of Oral Surgery, Nagaoka Red Cross Hospital.

Blood samples were taken after obtaining the patients' informed consent to participate in the study and processed anonymously. All cases were diagnosed histopathologically as OSCC. The study protocol was approved by the ethics committees of each institution.

\section{Genotyping of MMP-I and MMP-3}

$5 \mathrm{ml}$ of blood was obtained from the subjects and used as the source of peripheral blood lymphocytes. $0.2 \% \mathrm{NaCl}$ was added for destruction of red blood cells, followed by addition of TNE buffer, 10\% SDS and Proteinase K (MERCK Co., Darmstadt, Germany). After incubation at $58^{\circ} \mathrm{C}$ for more than six hours, genomic DNA was extracted by phenol-chloroform treatment and ethanol precipitation. The reaction was performed in a $25 \mu \mathrm{l}$ volume made up of $70 \mathrm{ng}$ genomic DNA, $2.25 \mu \mathrm{l}$ of the specific forward/reverse primer $(10 \mu \mathrm{M}), 1 \mu \mathrm{l}$ of TaqMan ${ }^{\circledR}$ MGB probes $(5 \mu \mathrm{M}), 12.5 \mu$ l of TaqMan ${ }^{\circledR}$ Universal Master Mix (Applied Biosystems, Foster City, CA, USA). PCR cycling conditions were $10 \mathrm{~min}$ of initial denaturation at $95^{\circ} \mathrm{C}$ followed by 35 cycles of $15 \mathrm{sec}$ denaturation at $92^{\circ} \mathrm{C}$ and $1 \mathrm{~min}$ of one step annealing/extension at $60^{\circ} \mathrm{C}$ for $M M P-1$ or $62^{\circ} \mathrm{C}$ for MMP-3 (ABI Prism ${ }^{\circledR} 7900 \mathrm{HT}$ Sequence Detection System, Applied Biosystems). Combination of the probe/primer used for the MMP-1 SNP were: 
Forward primer, 5'-TGCCACTTAGATGAGGAAATTGTAGT-3' and reverse primer, 5'-ACACTTTCCTCCCCTTATGGATTC-3', TaqMan ${ }^{\circledR}$ MGB probes, FAM for 1G, 5'ATAATTAGAAAGATATGACTTATC-3' and VIC for 2G, 5'ATAATTAGAAAGGATATGACTTAT-3'; used for the MMP3 SNP were: Forward primer, 5'-ACATCACTGCCACCACTCTGTT-3' and reverse primer, 5'-GGCACCTGGCCTAAAGACATT-3', TaqMan ${ }^{\circledast}$ MGB probes, FAM for 5A, 5'-AAGACATGGTTTTTC-3' and VIC for 6A, 5'-AGACATGGTTTTTTC-3'.

\section{Statistical analysis}

The Chi-square test was used to examine the differences in genotype distribution of the MMP-1 and MMP-3 promoters between the OSCC cases and control groups, and to estimate correlation or synergistic effects of $M M P-1$ genotypes with regard to clinical consequences as well as environmental factors among the OSCC cases. A $p$-value of < 0.05 was considered as statistically significant. Univariate analysis was performed by Fisher's exact test (two-sided) on gender, carrier state of MMP-1 $1 \mathrm{G}$ allele (1G+ or 1G-) and $2 \mathrm{G}$ allele (2G+ or $2 \mathrm{G}$-) between the OSCC and control groups. In the consideration of latent interrelations between factors, the effects of MMP-1 2G allele, age and gender were estimated by a multivariate logistic regression model. For each parameter, the OSCC risk was accounted by Odds Ratios (OR) and 95\% Confidence Intervals (95\% $\mathrm{CI}$ ). All of the statistical analyses were performed using the SPSS 11.5J software package (SPSS Japan Inc., Tokyo, Japan).

\section{Results}

Genotype distributions of MMP-I and MMP-3 promoter polymorphisms in OSCC cases and control groups

The genotype distributions of the promoter SNPs in $M M P-1$ and $M M P-3$ genes did not indicate a departure from the Hardy-Weinberg equilibrium when they were examined separately in the OSCC $(n=170)$ and control $(\mathrm{n}=164)$ groups, or in all the samples combined $(\mathrm{n}=$ $334)\left(\chi^{2}<3.84, p>0.05\right)$. The frequency of $1 \mathrm{G} / 2 \mathrm{G}$ or $2 \mathrm{G} /$ $2 \mathrm{G}$ promoter genotypes having the $2 \mathrm{G}$ allele, which is associated with a high $M M P-1$ expression level, was significantly higher in the OSCC group, and the frequency of
Table I: MMP-I and MMP-3 genotype distribution in OSCC cases and controls

\begin{tabular}{cccc}
\hline & $\begin{array}{c}\text { OSCC cases } \\
(n=170)\end{array}$ & $\begin{array}{c}\text { Controls } \\
(n=164)\end{array}$ & P \\
\hline $\begin{array}{c}\text { MMP-I } \\
\text { 2G/2G }\end{array}$ & $77(45.3)$ & $64(39.0)$ & 0.034 \\
IG/2G & $79(46.5)$ & $71(43.3)$ & \\
IG/IG & $14(8.2)$ & $29(17.7)$ & \\
& & & \\
MMP-3 & & $8(4.9)$ & 0.188 \\
$5 \mathrm{~A} / 5 \mathrm{~A}$ & $3(1.8)$ & $54(32.9)$ & \\
$5 \mathrm{~A} / 6 \mathrm{~A}$ & $50(29.4)$ & $102(62.2)$ & \\
6A/6A & $117(68.8)$ & &
\end{tabular}

The data were analyzed by the $\chi^{2}$ test.

the $1 \mathrm{G} / 1 \mathrm{G}$ homozygote was lower than that of the control group ( $p=0.034$, Table 1$)$. On the other hand, no difference in $M M P-3$ genotype distribution (5A/5A, 5A/6A, and $6 \mathrm{~A} / 6 \mathrm{~A})$ was detected between the OSCC case and control groups.

\section{Association between MMP-I promoter genotypes and various clinical parameters}

$M M P-1$ promoter genotypes of OSCC cases were stratified by clinical parameters including gender, age (Table 2), T category, lymph-node metastasis ( $\mathrm{N}$ category), tumor location in the oral cavity, status of alcohol intake and smoking (Table 3). A significant association was detected only between the age and MMP-1 genotype, which suggests accumulation of older age patients with the $1 \mathrm{G}$ allele, or young age patients with the $2 \mathrm{G}$ allele. Figure 1 shows the age distribution pattern of subjects with MMP1 promoter genotypes in OSCC groups, demonstrating a remarkable reduction of the $1 \mathrm{G} / 1 \mathrm{G}$ and $1 \mathrm{G} / 2 \mathrm{G}$ genotype distributions in OSCC cases less than 45 years and 35 years old. Receiver operating characteristic (ROC) curve consistently exhibited that the 45 years of age could be an optimal cutoff value of the age at which to stratify the young OSCC from the older bracket in following analyses. It was of considerable interest to notice that the MMP-1 promoter genotype has a remarkable difference in distribution between subjects over and under 45 years of age. A

Table 2: Age and gender distribution in relation to alleles in cases and controls

\begin{tabular}{|c|c|c|c|c|c|c|c|c|}
\hline & \multicolumn{4}{|c|}{ OSCC cases } & \multicolumn{4}{|c|}{ Controls } \\
\hline & $2 \mathrm{G} / 2 \mathrm{G}$ & $I G / 2 G$ & $I G / I G$ & $p$ & $2 \mathrm{G} / 2 \mathrm{G}$ & $1 \mathrm{G} / 2 \mathrm{G}$ & $I G / I G$ & $p$ \\
\hline Age* & $54.8 \pm 15.1$ & $57.5 \pm 13.2$ & $60.1 \pm 10.9$ & 0.277 & $52.2 \pm 14.8$ & $52.3 \pm 14.5$ & $48.1 \pm 14.2$ & 0.387 \\
\hline \multicolumn{9}{|l|}{ Gender\# } \\
\hline males & 46 (59.7\%) & $53(67.1 \%)$ & $8(57.1 \%)$ & 0.570 & 38 (59.4\%) & 46 (64.8\%) & $20(69 \%)$ & 0.640 \\
\hline females & 31 (40.3\%) & $26(32.9 \%)$ & $6(42.9 \%)$ & & 26 (40.6\%) & 25 (35.2\%) & $9(3 \mid \%)$ & \\
\hline
\end{tabular}

Data are expressed as mean \pm SD or number of subjects (\%).

* One-way ANOVA test.

\# $\chi^{2}$ test. 
significant difference was demonstrated in susceptibility to OSCC in individuals less or more than 45 years old ( $p$ $=0.002, \mathrm{OR}=2.26,95 \% \mathrm{CI}=1.35-3.79)($ Table 4$)$. No association was observed with the $1 \mathrm{G}$ allele $(1 \mathrm{G} / 1 \mathrm{G}$ and $1 \mathrm{G} / 2 \mathrm{G} ; p=0.294, \mathrm{OR}=1.29,95 \% \mathrm{CI}=0.84-2.00$, whereas a significantly elevated risk of OSCC was exhibited with the $2 \mathrm{G}$ allele $(2 \mathrm{G} / 2 \mathrm{G}$ and $1 \mathrm{G} / 2 \mathrm{G} ; p=0.016$, OR $=2.39,95 \% \mathrm{CI}=1.21-4.72$. The environmental factors, alcohol intake and smoking status were stratified with $M M P-1$ genotype distributions in OSCC cases, but no significant association was demonstrated of either factor with the MMP-1 genotype distribution (Table 3).

\section{Multivariate analyses of MMP-I allele frequencies and clinical parameters}

Logistic regression analysis of OSCC in relation to age, gender, and presence of the $1 \mathrm{G}$ and $2 \mathrm{G}$ alleles revealed that subjects of 45 years old and older had a 2.47-fold significantly increased risk of OSCC $(p=0.0006,95 \% \mathrm{CI}=$
1.47-4.14) and that those carrying the MMP-1 $2 \mathrm{G}$ allele had a 2.30 -fold significantly elevated risk $(p=0.018$, $95 \% \mathrm{CI}=1.15-4.58)$. Thus it was demonstrated that age and the presence of the $2 \mathrm{G}$ allele were independently associated with OSCC onset (Table 5).

\section{Discussion}

In this study, we examined SNPs in the promoter regions of $M M P-1$ and $M M P-3$ genes in relation to OSCC risk with case-control analyses. Significant differences, i.e., high frequency of $2 \mathrm{G} / 2 \mathrm{G}$ genotype and decreased frequency of $1 \mathrm{G} / 1 \mathrm{G}$ genotype, were observed in the MMP-1 genotype distribution in OSCC cases $(p=0.034$, Table 1$)$. Similarly, in comparisons of allele frequency a significant correlation was detected between onset of OSCC and genotypes that carry the MMP-1 promoter $2 \mathrm{G}$ allele in homo- or hetero-form $(p=0.016$, OR $=2.39$, 95\%CI $=1.21-4.72)$. $\mathrm{MMP}-1$ with the $2 \mathrm{G}$ type promoter caused a higher expression level of MMP-1 in tissues [11]. The biological mech-

Table 3: Relation of MMP-I genotypes to clinical parameters and environmental factors among the OSCC cases

\begin{tabular}{|c|c|c|c|c|}
\hline & $2 \mathbf{G} / 2 \mathbf{G} n(\%)$ & IG/2G n (\%) & IG/IG $n(\%)$ & $p$ \\
\hline Total & $77(45.3)$ & $79(46.5)$ & $14(8.2)$ & \\
\hline \multicolumn{5}{|l|}{ Gender } \\
\hline Male & $46(45.9)$ & $53(47.5)$ & $8(7.4)$ & 0.57 \\
\hline Female & $31(47.2)$ & $26(41.3)$ & $6(7.5)$ & \\
\hline \multicolumn{5}{|l|}{ Age } \\
\hline (years $\pm S D)$ & $54.8 \pm 15.1$ & $57.5 \pm 13.2$ & $60.1 \pm 10.9$ & $0.277^{*}$ \\
\hline \multicolumn{5}{|l|}{ T category } \\
\hline $\mathrm{TI}-2$ & $55(45.1)$ & $58(47.5)$ & $9(7.4)$ & 0.78 \\
\hline T3-4 & $22(45.8)$ & $21(43.8)$ & $5(10.4)$ & \\
\hline \multicolumn{5}{|l|}{$\mathbf{N}$ category } \\
\hline No & $50(43.9)$ & $53(46.5)$ & II (9.6) & 0.607 \\
\hline $\mathrm{NI}-3$ & 27 (48.2) & $26(46.4)$ & $3(5.4)$ & \\
\hline \multicolumn{5}{|l|}{ Tumor location } \\
\hline Tongue & $45(54.9)$ & $31(37.8)$ & $6(7.3)$ & $0.260 \#$ \\
\hline Lower gingiva & $14(35)$ & $24(60)$ & $2(5)$ & \\
\hline Oral floor & $6(35.3)$ & $9(52.9)$ & $2(11.8)$ & \\
\hline Buccal mucosa & $3(2 \mid .4)$ & $9(64.3)$ & $2(14.3)$ & \\
\hline Upper gingiva & $7(53.8)$ & $5(38.5)$ & I (7.7) & \\
\hline Palate & $2(50)$ & $\mathrm{I}(25)^{\prime}$ & $\mathrm{I}(25)$ & \\
\hline \multicolumn{5}{|l|}{ Alcohol intake } \\
\hline Drinker & 45 (45.9) & 45 (45.9) & $8(8.2)$ & 0.982 \\
\hline Non-drinker & $32(44.4)$ & $34(47.2)$ & $6(8.3)$ & \\
\hline \multicolumn{5}{|l|}{ Smoking status } \\
\hline Smoker & $39(44.3)$ & $43(48.8)$ & $6(6.8)$ & 0.702 \\
\hline Non-smoker & $38(46.3)$ & $36(43.9)$ & $8(9.8)$ & \\
\hline
\end{tabular}

T and N categories were according to the UICC TNM classification of malignant tumors for lip and oral cavity. The data were analyzed by the $\chi^{2}$.

* One-way ANOVA test.

\# Fisher's exact tests. 
Table 4: Univariate analysis of predictive factors

\begin{tabular}{ccccc}
\hline & OSCC & Controls & $p$ & OR (95\% CI) \\
\hline $\begin{array}{c}\text { Age } \\
<45\end{array}$ & 29 & 52 & & \\
$\geqq 45$ & 141 & 112 & & \\
$\begin{array}{c}\text { Gender } \\
\text { Male }\end{array}$ & 107 & 104 & & \\
$\begin{array}{c}\text { Female } \\
\text { IGa }\end{array}$ & 63 & 60 & & \\
- & 77 & 64 & & \\
+ & 93 & 100 & & \\
+ & 14 & 29 & $0.002(1.35-3.79)$ \\
$\mathbf{2 G}$ & 156 & 135 & & \\
- & & & & \\
+ & & & &
\end{tabular}

a: IG- denotes $2 \mathrm{G} / 2 \mathrm{G}$, and IG+ denotes IG/IG or IG/2G. $\boldsymbol{b}$ : $2 \mathrm{G}$ denotes $I G / I G$, and $2 \mathrm{G}+$ denotes $2 \mathrm{G} / 2 \mathrm{G}$ or $\mathrm{IG} / 2 \mathrm{G}$.

Data were analyzed by Fisher's exact test. The odds ratio and $95 \% \mathrm{Cl}$ were calculated.

anism of the elevated risk of OSCC as related to the $2 \mathrm{G}$ allele of $M M P-1$ promoter includes genetic instability, which is accompanied by the cell cycle activation caused by a sequence of events led by increased MMP-1 enzyme activity, i.e. activation of tissue disruption, reconstruction and resultant release of ECM binding growth factors. The relationship between MMP-1 promoter polymorphism and risk of OSCC has been investigated by Lin et al. in a group of 121 cases [22] and by Cao et al. in a group of 96 cases [23] and by Vairaktaris et al. in a group of 156 cases [24]. Although both Lin et al. and Cao et al.reported an elevation of OSCC risk correlated with the MMP-1 2G allele, further studies were needed to reach a conclusion mainly because the numbers of cases in the previous studies were relatively small, and there were differences between these reports in background analyses on correlation with environmental risk factors, such as smoking and areca use. In this study, significant correlations were found between the presence of the MMP-1 promoter $2 \mathrm{G}$ allele and increased OSCC risk among 170 Japanese OSCC patients. These results are consistent with existing reports on malignant neoplasms in general. It is notable that a new finding on the molecular function of MMP-1 in the onset of OSCC was obtained from the characteristic pattern of the MMP-1 promoter genotype distribution in younger patients.

Interestingly, Vairaktaris et al. reported an increased risk of oral cancer with MMP-1 1G/2G polymorphism [24]. The discrepancy of the results of the Chinese studies and our report on one hand and the European (German and Greek) study on the other hand may be explained by the diverse ethnic background of the different studied populations. Another point of difference is the fact that their patient sample included patients with positive family history of thrombophilia.

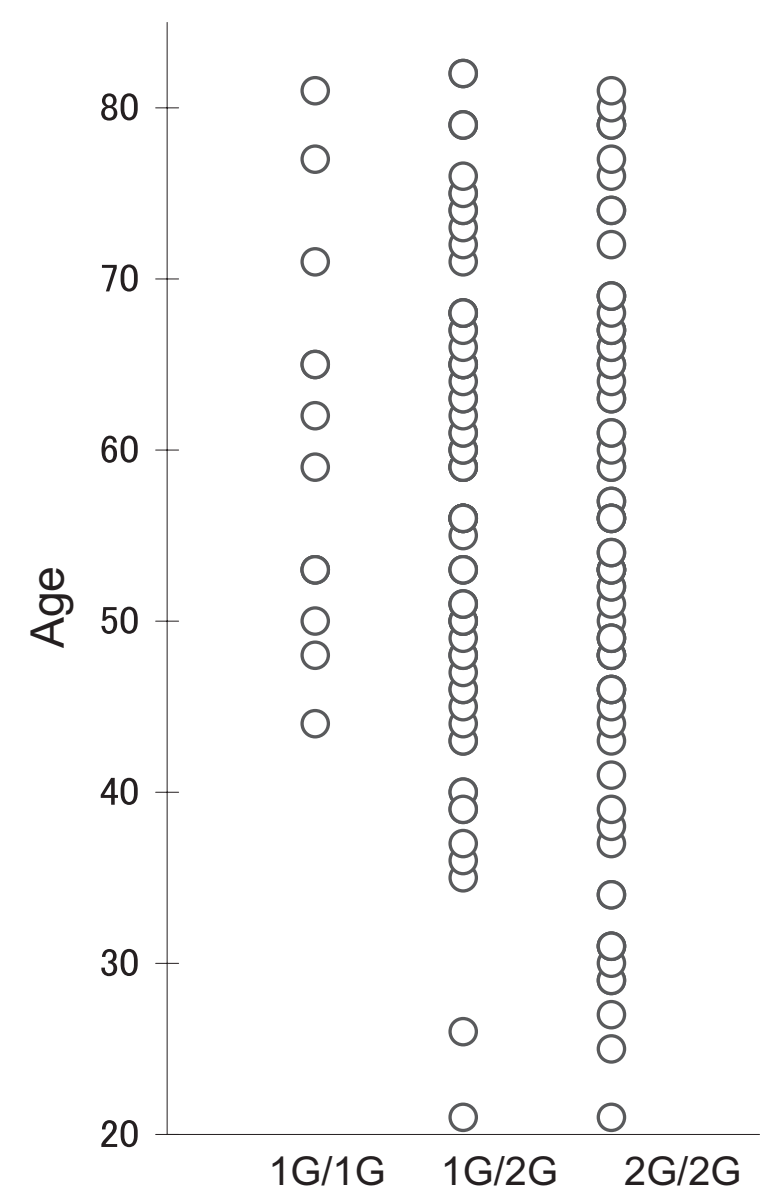

Figure I

Age distribution of the MMP-I genotypes in 170 OSCC cases between the ages of 20 and 80 years. The frequency of the IG/IG genotype is notably low. Note the clear reduction of the IG/IG and IG/2G genotype distributions in individuals under the ages of 45 and 35 years, respectively.

The observed bias of the average age by the MMP-1 promoter genotype among the 170 OSCC cases of this study suggested an influence of the MMP-1 promoter $2 \mathrm{G}$ allele on the age of OSCC onset. The scatter plot of age on the MMP-1 promoter genotypes also revealed disappearance of the 1G/1G-genotype distribution among the OSCC cases under 45 years old. In agreement with this observation, the ROC analysis suggested that the age of 45 years is the borderline age above which a change occurs in the incidence of OSCC. Although the specific reasons for these results have not been clarified, they suggest that some kind of biological conditions related to carcinogenesis have initiated around the age of 45 . Carcinogenesis is caused by synergistic effects of various factors $[25,26]$. The multivariate logistic regression analysis showed that aging 
Table 5: Multivariate analysis of factors affecting OSCC

\begin{tabular}{|c|c|c|c|c|}
\hline \multicolumn{5}{|c|}{ A Results of factors affecting OSCC } \\
\hline & $\beta$ coefficient & OR & $95 \% \mathrm{Cl}$ of OR & $\mathbf{p}$ \\
\hline 2G+ & 0.83 & 2.30 & $(1.15-4.58)$ & 0.0180 \\
\hline Age & 0.90 & 2.47 & $(1.47-4.14)$ & 0.0006 \\
\hline \multicolumn{5}{|c|}{ B Results showing the alleles independently associated with OSCC (adjusted for age and gender). } \\
\hline Allele & $\beta$ coefficient & OR & $95 \% \mathrm{Cl}$ of OR & $p$ \\
\hline $\mathbf{I G / 2 G}$ & 0.782 & 2.187 & $(1.06-4.5 \mathrm{I})$ & 0.034 \\
\hline $2 \mathbf{G} / 2 \mathbf{G}$ & 0.907 & 2.476 & $(1.20-5.13)$ & 0.015 \\
\hline
\end{tabular}

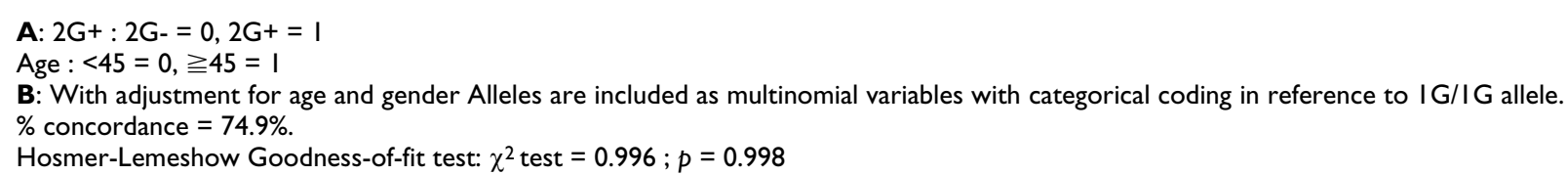

and presence of the MMP-1 2G allele (i.e., 2G/2G or $1 \mathrm{G} /$ $2 \mathrm{G})$ are independently involved in onset of OSCC. In fact, it was clarified that the significance of the presence of the MMP-1 2G allele was lower in the subject group 45 years old or older $(p=0.238, \mathrm{OR}=1.65,95 \% \mathrm{CI}=0.75-3.55)$, and that the impact of the allele was highly significant in the younger group, which was under 45 years old ( $p=$ $0.014, \mathrm{OR}=9.67,95 \% \mathrm{CI}=1.20-78.15)($ data not shown).

As concrete causes of OSCC, mainly tobacco smoking and alcohol usage and, in some cases, viral infections have attracted attention as environmental causative factors $[25,27]$. It has been suggested that tobacco smoking and alcohol usage alone may not explain the mechanism of the entire early onset of OSCC, because the duration of exposure to these risk factors in young OSCC patients is shorter than in the older group, and also because there are some cases with stable incidence that have no known risk factors [28]. The association with smoking and habitual drinking has been supported as the risk factors of OSCC, which generally shows a higher incidence in older age, but other investigators believe that the mechanism of the early onset OSCC is fundamentally different from that of elderly onset OSCC [25]. Cao et al. considered the relationship with smoking as a behavioral risk factor and the MMP-1 2G allele as a genetic risk factor in the OSCC group [23]. In lung cancer, it has been similarly shown that a genetic factor of the MMP-1 promoter $2 \mathrm{G}$ allele increases the risk of cancer that occurs in a tobacco-usagedependent manner only in cases with a history of tobacco use. These reports support the role of $M M P-1$ promoter polymorphism as an endogenous background factor, in contrast to exogenous environmental factors [15]. However, no evidence to support a notion of synergistic interactions between risk factors, such as habitual smoking and drinking and $M M P-1$ promoter polymorphism in
OSCC cases, was shown in this study. Further investigations with regard to frequency and duration of exposure are required to consider interactions between environmental factors and multiple genetic background factors.

Examples are known of malignant neoplasms caused by genetic factors, for example, mutations in $R B$ in Retinoblastoma [29], p53 in Li-Fraumeni Syndrome [30], and $A P C$ in familial adenomatous polyposis [31]. There are also reports of mutations in BRCA1 and BRCA2, which affect familial breast cancer occurrence, though their penetrance is low [32]. These are neoplasms that are all caused by loss-of-function mutations in molecules functionally classified as tumor-suppressor genes, and they are characterized by familial, juvenile or young onset and may be multicentric or bilateral. Although incidents are rare in the population, they are examples of germline mutations that directly involve heterofamilial tumorigenesis.

By contrast, the $M M P-1$ promoter $2 \mathrm{G}$ allele is a genetic polymorphism that exists at the high allele frequency of $80 \%$ to $90 \%$ in the general population. It is possible to call this a hereditary trait that is shared among races or humans in general. Other genetic factors that are classified into similar polymorphism as MMP-1 have also been reported, such as Cyclin D1 (CCND1) in head and neck squamous cell carcinoma (HNSCC) and colorectal cancer $[33,34]$, xeroderma pigmentosum complementary group $\mathrm{D}(X P D)$, DNA damage binding protein 2 (DDB2), and $M M P-9$ in lung cancer [35-37]. Similar to the effects of mutations in tumor suppressor genes, diversity in gene expression level and molecular structure caused by genetic polymorphisms affect monitoring and repair mechanism of DNA replication, as well as control of the cell cycle, ultimately resulting in genetic instability. The common mechanism of carcinogenesis caused by those genetic fac- 
tors is an elevated carcinogenic risk due to this genetic instability.

As examples of genetic polymorphisms that affect onset age of cancers other than that examined in this study, some reports discuss $M M P-1$ and DDB2 in lung cancer $[15,36]$, and CCND1 in HNSCC and colorectal cancer $[33,34]$. These genetic factors, on the other hand, are present in patients with cancer as well as in the general population at certain frequencies. Therefore, it is hard to conclude that these genetic factors are the primary factors in early onset carcinogenesis, unlike germline single-gene mutations in $R b$ and $A P C$ that induce juvenile or early onset of cancers with high penetrance. Aging brings exposure to various carcinogenic factors and is associated with inevitable accumulation of genetic and epigenetic modifications of genes. These accumulations interact synergistically with biological background factors on the host side, and consequently cancer may develop [26,38]. It seems that inherited genetic factors play a larger role in development of early onset cancer that has undergone a relatively short duration of exposure to carcinogen through environment and lifestyle habits. Therefore, it is conceivable that the impact of these genetic factors would appear more directly in younger than in older cases, although we still expect a synergistic involvement of various environmental and genetic factors. Nevertheless, because of the disappearance ofthe $M M P-1 \quad 1 \mathrm{G}$ allele distribution observed in the OSCC cases with a clear boundary under the age of 45 years, the MMP-1 promoter $2 \mathrm{G}$ allele should be recognized as an essential genetic precondition for the development of early onset OSCC.

It is said that an onset age of 45 years and younger accounts for about $6 \%$ of OSCC cases [27]. It should be noted that in this study we found that the tongue was the primary site in 25 cases $(86.2 \%)$ of 29 early onset OSCC cases in individuals under 45 years old. This primary site was obviously different from that in patients 45 years old and older in whom we noted 57 cases of tongue cancer (40.4\%) out of 141 OSCC cases. Similar tendencies have been reported in previous studies $[39,40]$. These findings suggest the possibility that each primary tumor sites in the oral cavity may be associated with differences in cancer susceptibility, specific carcinogenic stimulation, or genetic background. However, no environmental or genetic factors specific to a particular site of the oral mucosa have been identified for OSCC. It is conceivable that it would be important to carry out further investigations on genetic and environmental risk factors for each anatomical site of the oral regions, though we are not able to discuss this aspect of OSCC because the number of cases was inadequate in this study.

\section{Conclusion}

The number of cases in this study was relatively small; therefore, the conclusions may still be contingent upon confirmation in a larger study. To evaluate the conclusive impact of $M M P-1$ on OSCC risk, a sufficiently large number of cases or consistency among results from multiple age adjusted studies would be needed. Furthermore, although the MMP-1 promoter SNP-based determination of OSCC susceptibility has the potential to become a useful clinical tool, it is necessary to add a greater diversity of information for practical use. In the future, improvements in diagnosis of susceptibility and clinical application could become possible by incorporating multiple genetic and environmental risk factors into the prediction model for cancer occurrence. Information about the risk of various types of malignant neoplasm as well as OSCC is useful for prevention and early detection of cancer or for monitoring of postoperative recurrence. A diagnostic system for evaluating cancer risk is vital not only for improvement in treatment techniques but also as a theoretical foundation to build strategies for cancer prevention.

\section{Abbreviations}

Matrix metalloproteinase (MMP), single nucleotide polymorphism (SNP), oral squamous cell carcinoma (OSCC), odds ratio (OR), 95\% Confidence Intervals (95\% CI), receiver operating characteristic curve (ROC), head and neck squamous cell carcinoma (HNSCC).

\section{Competing interests}

The author(s) declare that they have no competing interests.

\section{Authors' contributions}

$\mathrm{RN}, \mathrm{MN}$ participated in the design of the study. RN, MN and AAN drafted and wrote the manuscript. NK participated in the statistical analysis. $\mathrm{RN}, \mathrm{MN}$ and AAN participated in the production of genotype data. RN, MN, KK, $\mathrm{MO}$ and $\mathrm{HK}$ participated in the acquisition and interpretation of data. RN, MI, HF, TK and AAN participated in the experimental studies. RN, MN, AAN, HH and SS carried out the clinical studies. SC, HY and RT participated in the review of the study. All authors read and approved the final manuscript.

\section{Acknowledgements}

The authors thank the staff of the Division of Dental Clinic and Oral Surgery of Nagaoka Red Cross Hospital for their contribution in collecting samples and the clinical data set. This investigation was supported by grants from the Japan Society for the Promotion of Science (Grants-in-Aid for Scientific Research; no. 12791235 and no. 18592171).

\section{References}

I. Ziober BL, Turner MA, Palefsky JM, Banda MJ, Kramer RH: Type I collagen degradation by invasive oral squamous cell carcinoma. Oral oncology 2000, 36(4):365-372. 
2. Kerkela E, Saarialho-Kere U: Matrix metalloproteinases in tumor progression: focus on basal and squamous cell skin cancer. Experimental dermatology 2003, I 2(2): 109-125.

3. Impola U, Uitto VJ, Hietanen J, Hakkinen L, Zhang L, Larjava H, Isaka $\mathrm{K}$, Saarialho-Kere U: Differential expression of matrilysin-I (MMP-7), 92 kD gelatinase (MMP-9), and metalloelastase (MMP-I2) in oral verrucous and squamous cell cancer. The Journal of pathology 2004, 202(I): I 4-22.

4. Brinckerhoff CE, Rutter JL, Benbow U: Interstitial collagenases as markers of tumor progression. Clin Cancer Res 2000 6(1 2):4823-4830.

5. Nagata M, Fujita $H$, Ida $H$, Hoshina $H$, Inoue T, Seki $Y$, Ohnishi $M$, Ohyama T, Shingaki S, Kaji M, et al.: Identification of potential biomarkers of lymph node metastasis in oral squamous cell carcinoma by cDNA microarray analysis. International journal of cancer 2003, 106(5):683-689.

6. Murray GI, Duncan ME, O'Neil P, McKay JA, Melvin WT, Fothergill JE: Matrix metalloproteinase- $I$ is associated with poor prognosis in oesophageal cancer. The Journal of pathology 1998, I85(3):256-26I.

7. Shiozawa J, Ito M, Nakayama T, Nakashima M, Kohno S, Sekine I: Expression of matrix metalloproteinase- $I$ in human colorectal carcinoma. Mod Pathol 2000, I 3(9):925-933.

8. Shima I, Sasaguri Y, Kusukawa J, Yamana H, Fujita H, Kakegawa T, Morimatsu M: Production of matrix metalloproteinase-2 and metalloproteinase-3 related to malignant behavior of esophageal carcinoma. A clinicopathologic study. Cancer 1992, 70( I 2):2747-2753.

9. Kurahara S, Shinohara M, lkebe T, Nakamura S, Beppu M, Hiraki A, Takeuchi H, Shirasuna K: Expression of MMPS, MT-MMP, and TIMPs in squamous cell carcinoma of the oral cavity: correlations with tumor invasion and metastasis. Head \& neck 1999 , $21(7): 627-638$.

10. Ye S: Polymorphism in matrix metalloproteinase gene promoters: implication in regulation of gene expression and susceptibility of various diseases. Matrix Biol 2000, I 9(7):623-629.

II. Rutter JL, Mitchell TI, Buttice G, Meyers J, Gusella JF, Ozelius LJ, Brinckerhoff CE: A single nucleotide polymorphism in the matrix metalloproteinase-I promoter creates an Ets binding site and augments transcription. Cancer research 1998 , 58(23):532I-5325.

12. Ye S, Eriksson P, Hamsten A, Kurkinen M, Humphries SE, Henney AM: Progression of coronary atherosclerosis is associated with a common genetic variant of the human stromelysin-I promoter which results in reduced gene expression. The Journal of biological chemistry 1996, 27 I (22): I 3055- I 3060.

13. Hinoda $Y$, Okayama N, Takano N, Fujimura K, Suehiro Y, Hamanaka Y, Hazama S, Kitamura Y, Kamatani N, Oka M: Association of functional polymorphisms of matrix metalloproteinase (MMP)-I and MMP-3 genes with colorectal cancer. International journal of cancer 2002, I 02(5):526-529.

14. Kanamori Y, Matsushima M, Minaguchi T, Kobayashi K, Sagae S, Kudo $\mathrm{R}$, Terakawa N, Nakamura Y: Correlation between expression of the matrix metalloproteinase-I gene in ovarian cancers and an insertion/deletion polymorphism in its promoter region. Cancer research 1999, 59(I7):4225-4227.

15. Zhu Y, Spitz MR, Lei L, Mills GB, Wu X: A single nucleotide polymorphism in the matrix metalloproteinase-I promoter enhances lung cancer susceptibility. Cancer research 200I, 6I(2I):7825-7829.

16. Nishioka Y, Kobayashi K, Sagae S, Ishioka S, Nishikawa A, Matsushima M, Kanamori Y, Minaguchi T, Nakamura Y, Tokino T, et al.: A single nucleotide polymorphism in the matrix metalloproteinasepromoter in endometrial carcinomas. Jpn J Cancer Res 2000, 9I(6):6I2-6I5.

17. Hirata H, Naito K, Yoshihiro S, Matsuyama H, Suehiro Y, Hinoda $Y$ : A single nucleotide polymorphism in the matrix metalloproteinase-I promoter is associated with conventional renal cell carcinoma. International journal of cancer 2003, 106(3):372-374.

18. Hashimoto $T$, Uchida $K$, Okayama N, Imate $Y$, Suehiro $Y$, Hamanaka $Y$, Ueyama $Y$, Shinozaki F, Yamashita $H$, Hinoda $Y$ : Association of matrix metalloproteinase (MMP)-I promoter polymorphism with head and neck squamous cell carcinoma. Cancer letters 2004, 2 I I (I): 19-24.

19. Ghilardi G, Biondi ML, Caputo M, Leviti S, DeMonti M, Guagnellini E, Scorza $R$ : A single nucleotide polymorphism in the matrix metalloproteinase-3 promoter enhances breast cancer susceptibility. Clin Cancer Res 2002, 8( I 2):3820-3823.

20. Sutinen M, Kainulainen T, Hurskainen T, Vesterlund E, Alexander JP, Overall CM, Sorsa T, Salo T: Expression of matrix metalloproteinases (MMP-I and -2) and their inhibitors (TIMP-I, -2 and -3 ) in oral lichen planus, dysplasia, squamous cell carcinoma and lymph node metastasis. British journal of cancer 1998, 77( I 2):2239-2245.

2I. Jordan RC, Macabeo-Ong M, Shiboski CH, Dekker N, Ginzinger DG, Wong DT, Schmidt BL: Overexpression of matrix metalloproteinase- $I$ and -9 mRNA is associated with progression of oral dysplasia to cancer. Clin Cancer Res 2004, I 0(1 9):6460-6465.

22. Lin SC, Chung MY, Huang JW, Shieh TM, Liu CJ, Chang KW: Correlation between functional genotypes in the matrix metalloproteinases-I promoter and risk of oral squamous cell carcinomas. J Oral Pathol Med 2004, 33(6):323-326.

23. Cao ZG, Li CZ: A single nucleotide polymorphism in the matrix metalloproteinase-I promoter enhances oral squamous cell carcinoma susceptibility in a Chinese population. Oral oncology 2006, 42(I):32-38.

24. Vairaktaris E, Yapijakis C, Derka S, Serefoglou Z, Vassiliou S, Nkenke E, Ragos V, Vylliotis A, Spyridonidou S, Tsigris C, et al:: Association of matrix metalloproteinase-I (-1607 IG/2G) polymorphism with increased risk for oral squamous cell carcinoma. Anticancer research 2007, 27(I A):459-464.

25. Llewellyn CD, Johnson NW, Warnakulasuriya KA: Risk factors for squamous cell carcinoma of the oral cavity in young people - a comprehensive literature review. Oral oncology 200I, 37(5):40I-4I 8.

26. Kuwano H, Kato H, Miyazaki T, Fukuchi M, Masuda N, Nakajima M, Fukai $Y$, Sohda M, Kimura $H$, Faried A: Genetic alterations in esophageal cancer. Surgery today 2005, 35(I):7-18.

27. Herrero R, Castellsague X, Pawlita M, Lissowska J, Kee F, Balaram P, Rajkumar T, Sridhar H, Rose B, Pintos J, et al.: Human papillomavirus and oral cancer: the International Agency for Research on Cancer multicenter study. Journal of the National Cancer Institute 2003, 95(23): I772-I 783 .

28. Llewellyn CD, Johnson NW, Warnakulasuriya KA: Risk factors for oral cancer in newly diagnosed patients aged 45 years and younger: a case-control study in Southern England. J Oral Pathol Med 2004, 33(9):525-532.

29. Lee WH, Bookstein R, Hong F, Young LI, Shew JY, Lee EY: Human retinoblastoma susceptibility gene: cloning, identification, and sequence. Science 1987, 235(4794): 1394-1399.

30. Wong P, Verselis SJ, Garber JE, Schneider K, DiGianni L, Stockwell $\mathrm{DH}$, Li FP, Syngal S: Prevalence of early onset colorectal cancer in 397 patients with classic Li-Fraumeni syndrome. Gastroenterology 2006, 130(I):73-79.

3I. Nishisho I, Nakamura Y, Miyoshi Y, Miki Y, Ando H, Horii A, Koyama K, Utsunomiya J, Baba S, Hedge P: Mutations of chromosome $5 \mathrm{q} 2 \mathrm{I}$ genes in FAP and colorectal cancer patients. Science 1991, 253(5020):665-669.

32. Golshan M, Miron A, Nixon AJ, Garber JE, Cash EP, Iglehart JD, Harris JR, Wong JS: The prevalence of germline BRCAI and BRCA2 mutations in young women with breast cancer undergoing breast-conservation therapy. American journal of surgery 2006, 192(I):58-62.

33. Huang WS, Tang R, Lin PY, Changchien CR, Chen JS, Chiang JM, Yeh CY, Wang JY, Hsieh LL: Impact of the cyclin DI A870G polymorphism on susceptibility to sporadic colorectal cancer in Taiwan. Diseases of the colon and rectum 2006, 49(5):602-608.

34. Zheng Y, Shen H, Sturgis EM, Wang LE, Eicher SA, Strom SS, Frazier $M L$, Spitz MR, Wei Q: Cyclin DI polymorphism and risk for squamous cell carcinoma of the head and neck: a case-control study. Carcinogenesis 200I, 22(8): I I95-II99.

35. Liang G, Xing D, Miao X, Tan W, Yu C, Lu W, Lin D: Sequence variations in the DNA repair gene XPD and risk of lung cancer in a Chinese population. International journal of cancer 2003, 105(5):669-673.

36. Hu Z, Shao M, Yuan J, Xu L, Wang F, Wang Y, Yuan W, Qian J, Ma H, Wang $Y$, et al.: Polymorphisms in DNA damage binding protein 2 (DDB2) and susceptibility of primary lung cancer in the Chinese: a case-control study. Carcinogenesis 2006, 27(7): $1475-1480$.

37. Hu Z, Huo X, Lu D, Qian J, Zhou J, Chen Y, Xu L, Ma H, Zhu J, Wei $\mathrm{Q}$, et al.: Functional polymorphisms of matrix metalloprotei- 
nase- 9 are associated with risk of occurrence and metastasis of lung cancer. Clin Cancer Res 2005, I I(15):5433-5439.

38. Ha PK, Califano JA: Promoter methylation and inactivation of tumour-suppressor genes in oral squamous-cell carcinoma. The lancet oncology 2006, 7(I):77-82.

39. Shiboski CH, Schmidt BL, Jordan RC: Tongue and tonsil carcinoma: increasing trends in the U.S. population ages 20-44 years. Cancer 2005, 103(9): 1843-1849.

40. Myers JN, Elkins T, Roberts D, Byers RM: Squamous cell carcinoma of the tongue in young adults: increasing incidence and factors that predict treatment outcomes. Otolaryngol Head Neck Surg 2000, I 22(I):44-5I.

\section{Pre-publication history}

The pre-publication history for this paper can be accessed here:

http://www.biomedcentral.com/1471-2407/7/187/pre pub

Publish with Bio Med Central and every scientist can read your work free of charge

"BioMed Central will be the most significant development for disseminating the results of biomedical research in our lifetime. "

Sir Paul Nurse, Cancer Research UK

Your research papers will be:

- available free of charge to the entire biomedical community

- peer reviewed and published immediately upon acceptance

- cited in PubMed and archived on PubMed Central

- yours - you keep the copyright

Submit your manuscript here:

http://www.biomedcentral.com/info/publishing_adv.asp 